\title{
CONTROLO DE QUALIDADE
}

Ricardo Tiago Moura

Ricardo Tiago Moura publicou os livros Um gato para dois (Hariemuj, 2013), Epístolas a D. (não edições, 2013), Espaço aéreo (Arqueria, 2014 - Brasil) e pequena indústria (Tea for One, 2016), além de poemas dispersos em revistas e antologias. Dedica-se também colagem. Vive em Køge, Dinamarca.

“[...] A forma de Controlo de qualidade não passa despercebida e conduz à revisão das práticas e dos gestos mais banais do leitor. Este volume (capa que envolve um conjunto de folhas presas por um elástico) obriga-nos, pois, a reflectir no acto de leitura não apenas enquanto faculdade mental mas como sendo igualmente uma actividade física, corporal Sacrificando o lado mais prático u págivida de ftsica, corporal. Sacrificando o lado mais pratico da púgina presa colada, Controlo de qualidade radicaliza ainda aquilo que já é a proposta de qualquer livro. Torna evidente a liberdade na experimentação oferecida pelo volume: lendo-o ao calhas, deixando páginas de lado (neste caso, soltas em cima da mesa, da cómoda, no chão), misturando-as propositada ou despropositadamente."

Elisabete Marques 


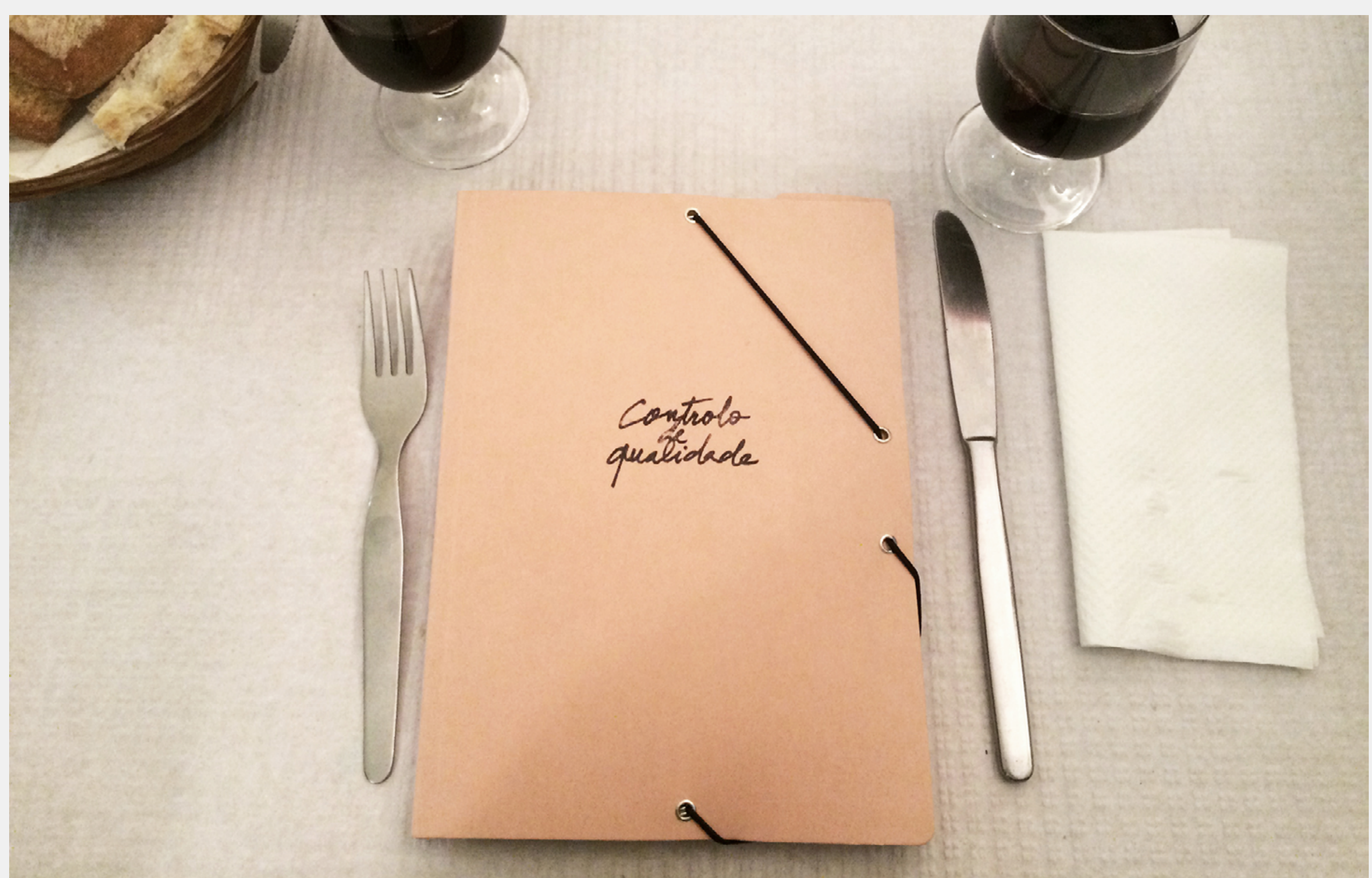

EM TESE

BELO HORIZONTE

v. 22

N. 3

SET.-DEZ. 2016

MOURA. Controlo de qualidade

P. $389-395$ 


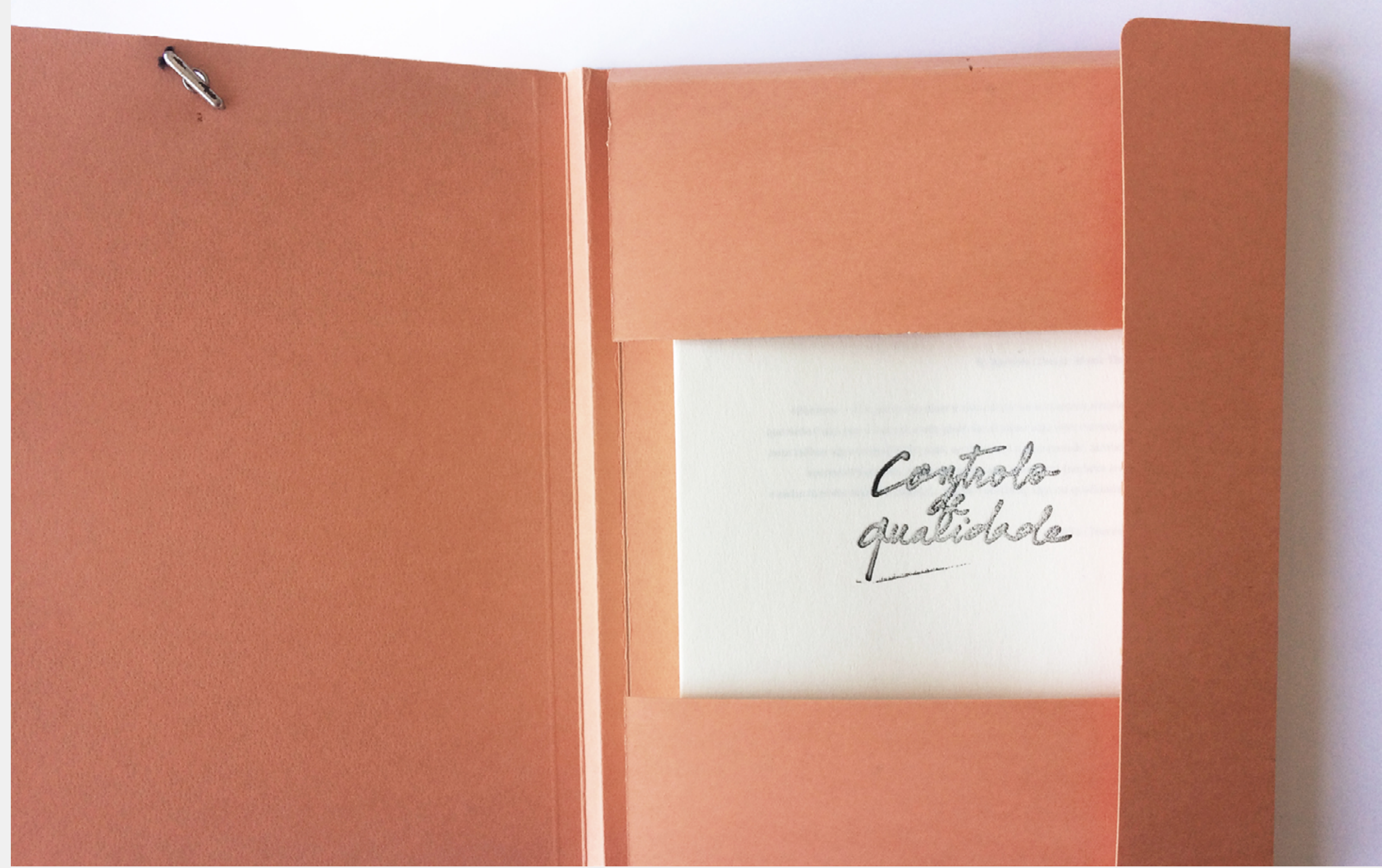




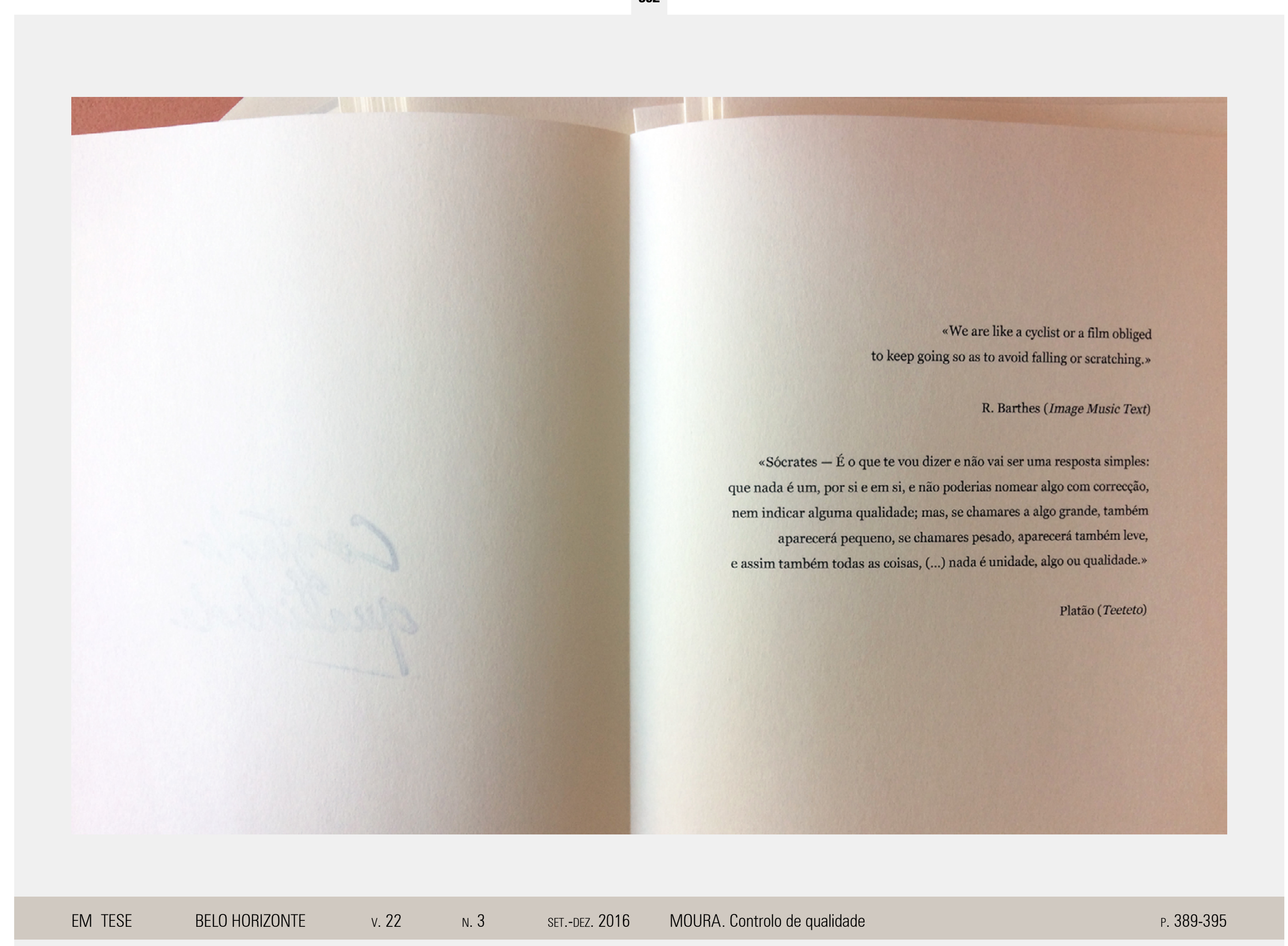

Poéticas 


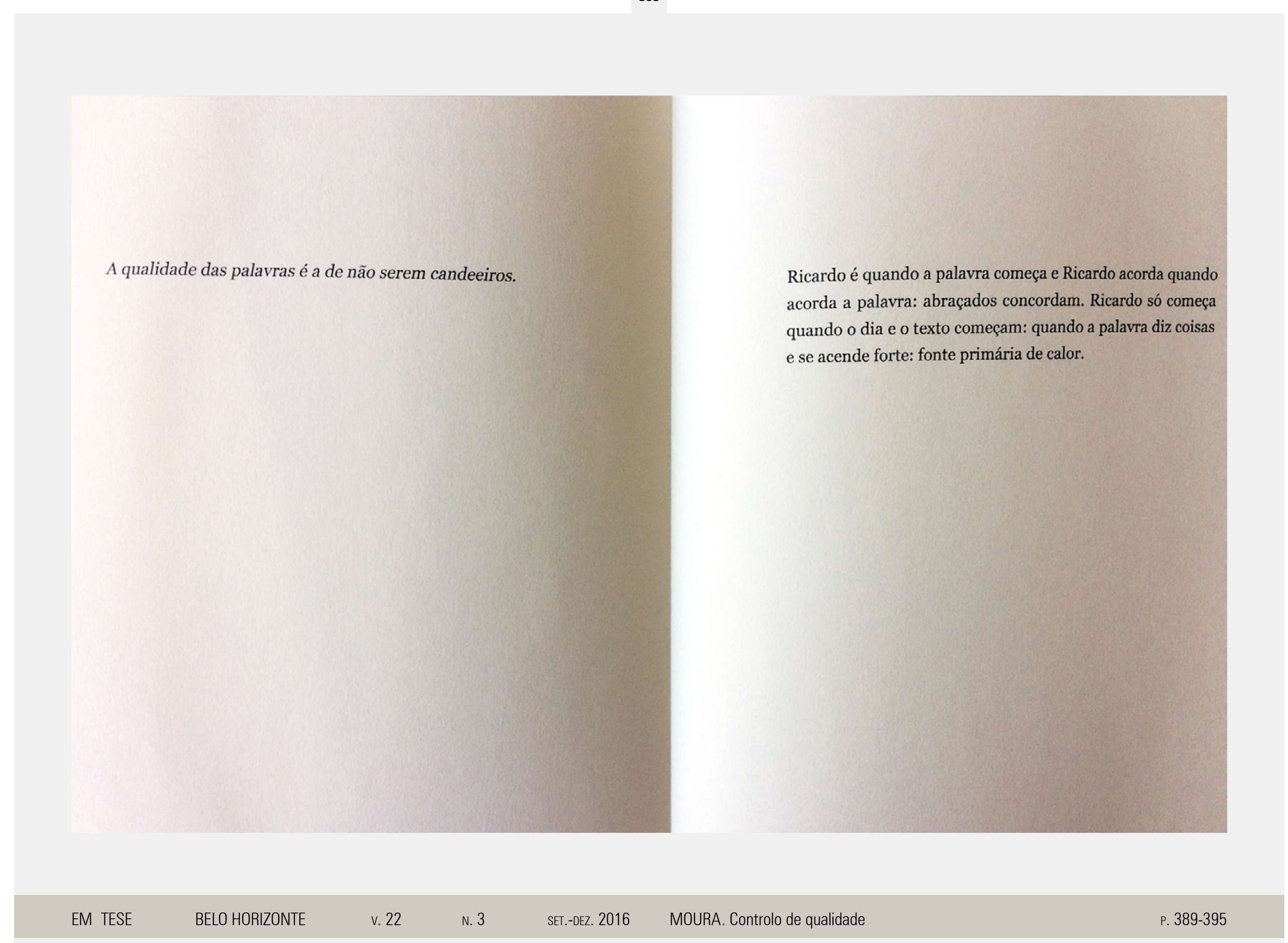

Poéticas 
/ CONTROLO de QUALIDADE /

(C) Ricardo Tiago Moura

/ Depósito legal 419658-16 / 60 exemplares /

/ escrito entre 2014 e 2015 / ed. do autor, Janeiro 2017 /

/ página 123 a partir de colagem do autor publicada na Revista eLyra / 


\section{DEPOIMENTO}

ao Ricardo (que não eu)!

A qualidade de uma coisa é sempre dupla, no mínimo. E a qualidade dos dias é a de se repetirem, vezes sucessivas. Os meus dias, entre 2014 e 2015, conduziram a uma vontade dupla: uma vontade de conversa: uma vontade de silêncio. Dias de estar sozinho e manter rotinas previsíveis. Dias de perder o lugar e ganhar amor aos aviões: o motor do som o nome. Dias sucessivos como são os dias de todos nós que começamos (todos os dias) actividades: tarefas: leituras: encontros: discursos. E se o discurso propuser uma verdade e uma forma, a dos próprios dias? Foi a pergunta que fiz antes de haver escrita: a mesma em cada página de Controlo de qualidade. Cada página só poderia ser dupla: diálogo.

A qualidade de um livro é a de ser lento. E foi lento o processo de escrita dos meus-nossos-vossos dias. Não seria um livro: nem um diário: nem um monólogo. Eco e espelho dos dias de Ricardo, mudando. A Qualidade pesa rigorosamente cada palavra. Ricardo pesando cada dia e cada página. Conversas ao telefone: a distância faz parte dos dias. Nuvens e cortes de energia fazem os dias feios. Trabalho e obrigações tornam os dias cheios. Demasiadas páginas. Falta ar nos livros: páginas vazias seriam precisas. Intervalos. A forma não é senão um reverso dos dias: do texto: lentos. Tudo verdade como nos dias, começando e terminando. A qualidade de um livro que fosse cíclico e próximo: compreensível e incompreensível: uma presença efectiva.

A qualidade de um texto é a de ser matéria plástica: múltipla, no mínimo. Experimentar o texto como se experimenta nos dias: errar, não errar, repetir, eliminar, aceitar, escolher controlar, não controlar. Materializar a vontade de conversa e de silêncio no texto: visualizar o texto: riscar o texto: procurar um texto que se perde sempre que pensamos ter chegado lá. Materializar o texto naqueles (nestes) dias rápidos e eficazes: a exterioridade da pele dos ecrãs: cansaços vários: contrários. Materializar contra a matéria: procurar um corpo para os dias todos: multiplicar. Materializar o temporário: dias que cabem numa caixa. 